\title{
Signalling entrepreneurs' credibility and project quality for crowdfunding success: cases from the Kickstarter and Indiegogo environments
}

\author{
Shuangfa Huang (D) - David Pickernell • Martina \\ Battisti • Thang Nguyen
}

Accepted: 8 March 2021 / Published online: 1 April 2021

(C) The Author(s) 2021

\begin{abstract}
In recent years, entrepreneurs have increasingly turned to crowdfunding, a new form of entrepreneurial finance, to fund projects. Whilst research has shown that signals originating from the entrepreneur and project can affect the outcome of crowdfunding, how different signals work together under different signalling environments remains underexplored. Drawing on signalling theory, we examine how signals of entrepreneurs' credibility (success, failure, backer and industry experience) and project quality (preparedness and thirdparty endorsements) produce crowdfunding success in different signalling environments. We collected a unique dataset with matched projects listed on both Kickstarter and Indiegogo, but with different funding models, to represent two distinct signalling environments. Results based on qualitative comparative analysis (QCA) identify two distinct signalling patterns that show entrepreneur's credibility and project quality signals can complement each
\end{abstract}

S. Huang $(\bowtie) \cdot$ D. Pickernell

Strategy, Enterprise and Innovation, Faculty of Business and Law, University of Portsmouth, Portsmouth, Hampshire, UK

e-mail: shuangfa.huang1@ port.ac.uk

M. Battisti

Management, Technologies and Strategy, Grenoble Ecole de Management, Grenoble, France

\section{T. Nguyen}

Centre for Financial \& Corporate Integrity, Coventry University, Coventry, UK other to produce crowdfunding success. In an environment with less uncertainty, entrepreneur's credibility in terms of crowdfunding experience can also compensate absent project quality to produce crowdfunding success. In an environment with higher uncertainty, entrepreneur's credibility and project quality need to be both present to establish the necessary legitimacy for crowdfunding to be successful. Furthermore, by integrating positive (i.e. success) and negative (i.e. failure) signals, we demonstrate how signal incongruence can enhance crowdfunding success.

Plain English Summary Failure experience is an important signal in achieving crowdfunding success, but its effectiveness depends on other signals as well as the signalling environment. Our study shows how crowdfunding success can be achieved in multiple ways and that the path to success depends on the funding model of the platform used. For entrepreneurs to demonstrate credibility, backer experience and project preparedness are important. Both are under the control of the entrepreneur and well worth considering investing effort into. Importantly, the study also shows that demonstrating failure experience is important in achieving crowdfunding success. Failure experience can either replace the lack of prior success experience by demonstrating a track record of learning or it can enhance prior success experience by producing a more realistic picture of the entrepreneurs. Thus, the study offers practical implications for entrepreneurs on how to use different 
signals to increase the likelihood of success in rewardbased crowdfunding.

Keywords Crowdfunding · Signalling theory · Qualitative comparative analysis (QCA) · Kickstarter . Indiegogo $\cdot$ Entrepreneurial Finance

\section{JEL classifications $\mathrm{G} 11 \cdot \mathrm{M} 13 \cdot \mathrm{L} 26$}

\section{Introduction}

Crowdfunding is a new form of entrepreneurial finance that has attracted increasing attention in recent years (Block et al., 2018). It allows entrepreneurs to draw on small contributions of funds from large numbers of individuals (the crowd) using internet platforms to fund their projects or support a particular goal (Mollick, 2014; Ahlers et al., 2015). Why do some crowdfunding projects receive support whilst others do not? To answer this question, researchers have explored and identified a wide range of factors that can affect crowdfunding success (for recent reviews, see Mochkabadi \& Volkmann, 2020; Colombo, 2020). For example, research has shown that entrepreneurs' social capital (Mollick, 2014; Colombo et al., 2015; Vismara, 2016; Butticè et al., 2017), human capital (Ahlers et al., 2015; Courtney et al., 2017; Piva \& Rossi-Lamastra, 2018), narcissism (Bollaert et al., 2020) and narrative styles (Cappa et al., 2020) all impact the outcome of crowdfunding.

Extensive research in entrepreneurial finance has therefore applied signalling theory to understand how entrepreneurs might leverage different signals to establish legitimacy for their entrepreneurial endeavours (Colombo, 2020; Mochkabadi \& Volkmann, 2020). In the context of crowdfunding, the literature suggests entrepreneurs can establish legitimacy for a crowdfunding project through leveraging their credibility and the project's quality. Research has found that entrepreneurs' credibility (particularly their previous crowdfunding experience) provides signalling benefits that enhance legitimacy and, in turn, increase chances of crowdfunding success (Zvilichovsky et al., 2015; Courtney et al., 2017; Davies \& Giovannetti, 2018). The reason is that crowdfunding experience demonstrates knowledge and credibility of entrepreneurs in crowdfunding, generating legitimacy spillovers having the potential to affect subsequent crowdfunding endeavours (Soublière \& Gehman, 2020). Studies have also found that signals of project quality can enhance the likelihood of crowdfunding success because they demonstrate the viability of the project (Mollick, 2014; Courtney et al., 2017), thus further establishing legitimacy for the endeavour. Taken together, previous studies have generated useful insights into the role of individual signals for crowdfunding success.

Increasing research has highlighted that it is also important to examine combinations of signals or signal sets (Drover et al., 2018). The reason being that multiple signals often operate at the same time (Connelly et al., 2011; Courtney et al., 2017; Drover et al., 2018) and the effectiveness of one signal can depend on another (Plummer et al., 2016). We believe that, first, individual signals might complement each other to enhance the signalling effect (e.g. additive effect). Supporting this view, Colombo et al. (2019), identify, in their IPO based research, that firms' affiliation with different parties signals their quality in different domains. More importantly, they show that multiple signals, conveying different information from one another, can be additive in creating more positive outcomes concerning IPO valuation. Second, the presence of some signals might compensate for the absence of others. For example, if crowdfunding experience is important for the success of a new project (Courtney et al., 2017), entrepreneurs who lack such experience might need to rely on other signals to compensate for their lack of credibility. Third, the different signals (e.g. success and failure experience) might compete with each other (Steigenberger \& Wilhelm, 2018). Whilst researchers have devoted increasing attention to the role of multiple signals in the signalling process, our understanding of how the interplays of multiple signals (e.g. complement, compensate and/or compete with each other) influence the outcome of crowdfunding remains limited.

The signalling literature has highlighted that the value of signals depends on the signalling environment (Janney \& Folta, 2006; Connelly et al., 2011; Colombo, 2020). Extant research on entrepreneurial finance in general and crowdfunding in particular, however, has devoted limited attention to the role of signalling environments in the signalling process. In particular, for reward-based crowdfunding where the crowd can receive nonmonetary rewards by contributing a small amount of money to a project (Bi et al., 2017), the majority of studies focus on one environment only. Some studies focus on the crowdfunding platform Kickstarter 
(Mollick, 2014; Butticè et al., 2017; Courtney et al., 2017; Davies \& Giovannetti, 2018), whilst others focus on the platform Indiegogo (Lagazio \& Querci, 2018; Cumming et al., 2019). As a result, we know little about whether and how the effectiveness of signals for crowdfunding success might depend on the signalling environments in which the signalling takes place. To get a better understanding of the signalling environment's role, it is crucial to examine the success of the same crowdfunding projects across different platforms.

Accordingly, this study aims to examine how signals of entrepreneurs' credibility and project quality work together to establish legitimacy and influence crowdfunding success under different signalling environments. To signal entrepreneurs' credibility, we distinguish between creator experience, the experience in creating a project that may lead to success or failure (Skirnevskiy et al., 2017), and backer experience, the experience in backing a project of others (Zvilichovsky et al., 2015). We also include industry experience, whether the project is launched by entrepreneurs with relevant industry experience, as a signal for entrepreneurs' credibility because relevant industry experience might lead to a better understanding of the problems and needs of customers (Delmar \& Shane, 2006; Kotha \& George, 2012). To signal project quality, we distinguish between project preparedness (Mollick, 2014; Bi et al., 2017; Courtney et al., 2017) and third-party endorsements (Calic \& Mosakowski, 2016). Project preparedness concerns the extent of efforts devoted by entrepreneurs on the campaign page as represented through the use of videos, images and texts (Colombo et al., 2015; Calic \& Mosakowski, 2016). Third-party endorsement concerns whether the project is endorsed by independent third parties such as media websites, blogs and newspapers (Calic \& Mosakowski, 2016).

To achieve our research aim, we adopt a configurational approach using qualitative comparative analysis (QCA). More specifically, we explore how signals of entrepreneurs' credibility (success, failure, backer and industry experience) and project quality (preparedness and third-party endorsements) work together to produce crowdfunding success under two distinct signalling environments-Kickstarter and Indiegogo. It is important to note that the signals of entrepreneurs' credibility cover the domains of both crowdfunding experience and business experience. Following Furnari et al. (2020), we adopt their model of configurational theorising consisting of a three-stage iterative process: scoping, linking and naming. Scoping identifies how relevant signals may form configurations, linking focuses on how the signals connect with one another, whilst naming involves labelling the individual configurations to identify their overarching, higher-level themes.

The entrepreneurial finance market includes a range of different crowdfunding platforms (Bessière et al., 2020; Wallmeroth et al., 2018). We focus on rewardbased crowdfunding, an important form of entrepreneurial finance, for three reasons. First, in contrast to equitybased crowdfunding where entrepreneurs sell a certain amount of equity to raise finance (Block et al., 2018), reward-based crowdfunding allows entrepreneurs to raise finance through offering a product or service as a reward. Hence, reward-based crowdfunding provides entrepreneurs with the opportunity to test the market and receive feedback (Viotto da Cruz, 2018). Second, the scale of reward-based crowdfunding is much higher than equity-based crowdfunding based on the number of projects launched and funded. Indeed, over 194,000 campaigns have been funded on the reward-based crowdfunding platform Kickstarter since it was launched in 2009 (Kickstarter, 2020). By contrast, around 1200 businesses have been funded on the equity-based crowdfunding platform Crowdcube since it was launched in 2011 (Crowdcube, 2020). Third, reward-based crowdfunding is likely to be more accessible than equity-based crowdfunding because the former is not limited to firms, meaning individual entrepreneurs can also use reward-based crowdfunding to raise finance.

We collected a unique dataset with 62 matched projects, listed on both Kickstarter and Indiegogo, but using different funding models such that Kickstarter projects use an all-or-nothing funding model and Indiegogo projects employ a keep-it-all funding model. The two platforms represent distinct signalling environment as they entail different levels of uncertainty for the crowd to back a project. For example, the crowd might perceive Kickstarter projects as being less risky than Indiegogo projects because the latter might be underfunded and have a higher chance of failure (Cumming et al., 2019). Our results identify two distinct signalling patterns that show that (a) entrepreneur's credibility and project quality signals can complement each other to produce crowdfunding success and (b) the presence of credibility can compensate lack of project quality. Specifically, in an environment with less uncertainty, entrepreneur's credibility in terms of 
crowdfunding experience can compensate absent project quality to produce crowdfunding success. In an environment with higher uncertainty, entrepreneur's credibility and project quality need to be both present to establish the necessary legitimacy for crowdfunding to be successful.

Our study contributes to the literature in several ways. First, it expands research on the entrepreneurial finance context of reward-based crowdfunding by showing how crowdfunding success results from the interplay of different signals (Colombo, 2020). We uncover that different signals can complement each other to produce crowdfunding success, and the presence of certain signals (e.g. credibility) can compensate for the absence of others (e.g. project quality). We not only identify multiple configurations that can produce the same outcome but also summarise them into two overarching patterns explaining the complex phenomenon of crowdfunding success in a more meaningful way (Furnari et al., 2020). This also constitutes a methodological contribution as we illustrate the use of QCA in crowdfunding research to encourage other scholars to apply it.

Second, contrary to previous research, our findings suggest that the signal of failure experience will not necessarily hamper crowdfunding success. The signal of failure experience can either substitute for lack of prior success experience or complement existing success experience to produce a more realistic picture of the entrepreneurs. This implies that examining individual failure and success signals in isolation may conceal their actual effect on the outcome of crowdfunding. This finding addresses recent calls to integrate positive and negative signals in crowdfunding studies to advance our understanding of how signal incongruence can enhance crowdfunding success (Colombo, 2020; Drover et al., 2018).

Third, in response to calls to consider the role of signalling environment in the signalling process (Connelly et al., 2011), we provide evidence showing how the effectiveness of signals for crowdfunding success is contingent on the signalling environment by using a unique dataset with matched projects listed on two platforms using different funding models. Additionally, our study expands crowdfunding research by showing how crowdfunding success can be achieved in multiple ways based on a configurational approach (Ragin, 2008). Lastly, our findings offer practical implications for entrepreneurs on how to leverage different signals to enhance the likelihood of crowdfunding success.
The rest of this paper is structured as follows. First, we review relevant literature and set out our research propositions. Then we present the research method and our empirical findings. We conclude by discussing our empirical findings and outlining the contributions, limitations and directions for future research.

\section{Theoretical framework}

Crowdfunding, as one important setting of entrepreneurial finance (Block et al., 2018), is characterised by information asymmetry and uncertainty (Courtney et al., 2017; Davies \& Giovannetti, 2018). Entrepreneurs launching crowdfunding projects possess more information about the prospect of the project compared to potential project backers (the crowd). Entrepreneurs also possess private information about their skills and capabilities not observable by others (Ghatak et al., 2007). Because the crowd lacks information about the entrepreneur and the project, it is difficult for them to make an objective evaluation of the project. Furthermore, backing a crowdfunding project entails substantial uncertainty because the crowd might "get neither promised rewards nor their money back" (McKenny et al., 2017, p. 297). Consequently, entrepreneurs face the challenge of demonstrating the legitimacy and potential of their projects, whilst the crowd faces the challenge of assessing the real potential of projects to support.

Based on signalling theory (Spence, 1973), one solution that reduces information asymmetry in crowdfunding is for the better-informed party, entrepreneurs, to provide signals to the less informed party, the crowd. The reason is that signals can demonstrate unobservable characteristics and establish legitimacy in the situation of information asymmetry (Kirmani \& Rao, 2000; Frydrych et al., 2014). Crowdfunding is, however, a high-noise environment requiring specific bundles of signals or signal sets to effectively attract a prospective investor's attention (Steigenberger \& Wilhelm, 2018; Drover et al., 2018). In the opaque context of crowdfunding, effectively transmitting the most relevant information is particularly challenging because entrepreneurs need to draw potential investors' attention to specific signal sets that convey legitimacy amongst the much wider range of signals that exist in the environment (Colombo, 2020). The crowd, as prospective investors, typically assess two attributes of legitimacy as a basis for their decision to back a project: the 
quality of a project (Ahlers et al., 2015) and the credibility of the entrepreneur (Courtney et al., 2017).

Entrepreneurs therefore rely on observable signals through their experience in crowdfunding and the characteristics of projects to demonstrate their credibility in crowdfunding as well as the viability of their projects. Evidence suggests signals of entrepreneurs' credibility can enhance the likelihood of crowdfunding success (Zvilichovsky et al., 2015; Courtney et al., 2017; Davies \& Giovannetti, 2018). Studies have also found that signals of project quality contribute to crowdfunding success (Mollick, 2014; Ahlers et al., 2015; Bi et al., 2017; Lagazio \& Querci, 2018).

However, these two different signal sets have mostly been researched in isolation and their combined effectiveness on crowdfunding success is still not well understood (Colombo, 2020). A comprehensive understanding of each of the two signal sets, how they complement or substitute for each other and under what conditions they complement or substitute each other, is therefore still missing.

\subsection{Signalling credibility and project quality}

for crowdfunding success: scoping the framework for analysis

\subsubsection{Signals of entrepreneurs' credibility}

Research in traditional entrepreneurial finance settings (e.g. angel finance and venture capital) has highlighted the importance of entrepreneurs' experience for gaining finance (Cope et al., 2004; Zhang, 2011; Mitteness et al., 2012). In the context of reward-based crowdfunding, we argue that previous crowdfunding experience of entrepreneurs signals their knowledge and credibility in crowdfunding, generating legitimacy. Crowdfunding experience includes creator experience (experience in creating a crowdfunding project) and backer experience (experience in backing others' projects) (Zvilichovsky et al., 2015). Since many crowdfunding projects fail to meet the funding goal (Skirnevskiy et al., 2017), we thus distinguish success experience from failure experience in creating a project. We also argue that previous industry experience of entrepreneurs represents another source of credibility because it allows entrepreneurs to better understand the problems, needs and expectations of customers within a specific industry (Delmar \& Shane, 2006; Behrens et al., 2012). We now discuss how the signals of entrepreneurs' crowdfunding experience and industry experience influence the outcome of crowdfunding.

Success experience Research in human capital suggests experience is an effective way to acquire task-related human capital (Unger et al., 2011). Previous success experience in creating a crowdfunding project demonstrates the knowledge and skills of entrepreneurs in crowdfunding (Courtney et al., 2017). As such, new projects launched by entrepreneurs who have had success experience might attract more support from the crowd. That is, the previous success experience will likely breed even more success in subsequent new projects. Supporting our view, research in entrepreneurial finance has shown that experienced entrepreneurs have a higher chance of raising venture capital than novice entrepreneurs (Zhang, 2011). Within the crowdfunding context, evidence suggests the success experience of entrepreneurs positively influence the likelihood of crowdfunding success in new projects (Courtney et al., 2017).

Success experience also represents a source of credibility for the entrepreneurs. The perceived credibility is valuable, especially in a situation of information asymmetry such as crowdfunding, because it allows entrepreneurs to gain trust from the crowd (Wehnert et al., 2019). As such, the crowd might perceive new projects launched by entrepreneurs who have success experience as more credible and trustworthy. Such projects can thus attract more support from the crowd and have a higher chance of success. It should be noted that success experience also signals a potential source of internal social capital, referred to as "digital social links with other individuals active on the same platform" (Butticè et al., 2017, p. 184) that entrepreneurs can tap into. For example, entrepreneurs can leverage internal social capital through promoting new projects to backers of previous successful campaigns (Skirnevskiy et al., 2017; Butticè et al., 2017).

Failure experience The crowd might perceive previous failure experience in different ways. On the one hand, the crowd might perceive failure experience as a liability as it implies entrepreneurs' lack of skills and capabilities (Gaskill et al., 1993), as well as lack of quality in previous projects. When failure experience is perceived in this way, the crowd might discount the likelihood of crowdfunding success for projects launched by entrepreneurs who have previously failed. Empirical findings on the discounting effect of failure experience in 
obtaining entrepreneurial finance are inconclusive. Zunino (2018), for example, found that investors discount entrepreneurs who have failure experience when signals of entrepreneurial skills are also absent. By contrast, Cope et al. (2004) found that the decisions of investors are not significantly influenced by entrepreneurs' failure experience as failure experience might be offset by a higher quality venture concept.

On the other hand, the crowd might perceive failure experience as a source of knowledge and learning that might contribute to the outcome of new projects. From the notion of learning-by-doing (Cope \& Watts, 2000), the experience in creating a crowdfunding project allows entrepreneurs to gain knowledge and skills in crowdfunding. Furthermore, the literature on entrepreneurial failure suggests the experience of venture failure can trigger learning of entrepreneurs about the business and themselves (Cope, 2011; Mueller \& Shepherd, 2014). The learning from failure experience in turn helps increase entrepreneurs' level of preparedness for future entrepreneurial endeavours. Following this view, we reason that learning from previous failure experience as well as the knowledge and skills developed will likely enhance the chance of success in new projects.

Backer experience In contrast to other forms of entrepreneurial finance where entrepreneurs mainly seek financing from potential investors (Wright, 2017), entrepreneurs can play two distinct roles in crowdfunding (Zvilichovsky et al., 2015; Davies \& Giovannetti, 2018). They can be project creators who seek contributions from the crowd or project funders who provide support for projects of others. Backer experience might influence the likelihood of crowdfunding success because it can serve as a signal of mutual identification. That is, backing projects of others allows entrepreneurs to develop a shared identity with other backers in the virtual community (Nahapiet \& Ghoshal, 1998). Mutual identification might induce individuals in the virtual community to provide support for entrepreneurs who have backer experience (Aaker \& Akutsu, 2009; Kromidha \& Robson, 2016). Individuals, for example, might support the project by providing funding or promoting the project to raise its visibility.

Beyond the signalling benefits from mutual identification, backer experience also demonstrates a source of vicarious learning (Kim \& Miner, 2007). Backing the project of others might allow entrepreneurs to learn and identify good practices that can be adopted in their crowdfunding projects. Furthermore, experience in backing others' projects might induce reciprocity from other entrepreneurs. Because of the feeling of mutual obligation (Coleman, 1988), for example, other entrepreneurs in the virtual community might contribute funds to the project or promote the project among their circles (Butticè et al., 2017). Therefore, we believe the signal of backer experience will contribute to the outcome of crowdfunding. Indeed, evidence suggests the number of projects backed by entrepreneurs positively enhances the likelihood of crowdfunding success (Davies \& Giovannetti, 2018).

Industry experience The signal of industry experience concerns whether entrepreneurs have relevant industry experience concerning the crowdfunding project. It is likely to influence the outcome of crowdfunding in two ways. First, the industry experience of entrepreneurs determines the project potential in addressing customer needs. Specifically, projects developed based on entrepreneurs' relevant industry experience are likely to have higher quality in addressing the needs of customers than those launched by entrepreneurs without relevant industry experience. The reason being that relevant industry expertise allows entrepreneurs to better understand the problems, needs and expectations of customers within a specific industry (Delmar \& Shane, 2006; Behrens et al., 2012; Kotha \& George, 2012). Indeed, ventures developed by entrepreneurs with relevant industry experience tend to outperform those launched by entrepreneurs without such experience (Siegel et al., 1993; Lerner \& Almor, 2002).

Second, the industry experience of entrepreneurs can also reduce the risk of project fulfilment. The relevant industry experience allows entrepreneurs to develop a deep understanding of how the industry works (Dimov, 2010; Kotha \& George, 2012), as well as how to forecast and navigate the resources and tasks required in managing a project (Cassar, 2006). It can thus contribute to the fulfilment of the crowdfunding project. Industry experience also implies entrepreneurs can leverage established relationships with suppliers and key stakeholders in the industry. As Delmar and Shane (2006, p. 223) noted, "social ties to suppliers and distributors are created over time through activity in an industry". The established relationships are invaluable in gaining support and commitment from suppliers and distributors that in turn can contribute to the fulfilment of the project. 
In short, we argue that success experience, failure experience, backer experience and industry experience can contribute to the outcome of crowdfunding because they signal the credibility of entrepreneurs. The former three experiences relate to tasks in the crowdfunding domain and industry experience relates to tasks in the business domain.

\subsubsection{Signals of project quality}

Research in crowdfunding has shown that project preparedness and third-party endorsement are project quality signals that can contribute to crowdfunding success (Mollick, 2014; Calic \& Mosakowski, 2016; Courtney et al., 2017). We now discuss how project preparedness and third-party endorsements might influence the likelihood of crowdfunding success.

Project preparedness The signal of project preparedness concerns the extent of efforts devoted by entrepreneurs on the campaign page as represented through the use of videos, images and texts (Colombo et al., 2015; Calic \& Mosakowski, 2016). Research suggests preparedness in business plan presentation is a signal of venture quality such that high preparedness positively influences entrepreneurs' chance of receiving funds from investors (Chen et al., 2009). Building on this view, Mollick (2014) argues that the preparedness on the campaign page signals the underlying quality of a crowdfunding project that in turn can influence the outcome of crowdfunding. Indeed, studies have found that project preparedness as shown through the use of videos, images and texts provides signalling benefits that can enhance the likelihood of crowdfunding success (Mollick, 2014; Courtney et al., 2017; Lagazio \& Querci, 2018). The reason being that they can demonstrate unobservable project quality and help reduce information asymmetry (Kunz et al., 2017).

The use of videos, images and text can be seen as "costless" signals, because they can be potentially provided by both high- and low-quality projects (see Steigenberger \& Wilhelm, 2018, or Di Pietro et al., 2020), as compared to costly signals of past success that may be more difficult to obtain. Yet emerging evidence has shown that the use of costless signals is also valuable in the crowdfunding context. In particular, evidence suggests costless signals such as providing detailed project description on the campaign page (Lagazio \& Querci, 2018) and using positive rhetoric, which conveys "hope, optimism, resilience, and confidence" (Anglin et al., 2018, p. 470), can also contribute to crowdfunding success. We believe videos and images can influence crowdfunding success for two reasons. First, the information conveyed through videos and images "indicates the product's technical feasibility and the project's market readiness that help potential backers to ascertain the project quality" (Courtney et al., 2017 , p. 270). Second, the information conveyed through videos and images also indicates that the projects are more likely to be at a more advanced stage rather than at early stage, meaning the project are more "investment ready" (Mason \& Harrison, 2004) and might thus attract more support from the crowd.

Third-party endorsements The signal of third-party endorsements refers to whether the project is endorsed by independent third parties such as media websites, blogs and newspapers (Calic \& Mosakowski, 2016). Investors often rely on third-party endorsements to assess the quality of new ventures and mitigate information gaps (Massa Saluzzo \& Alegre, 2021). Indeed, evidence suggests firms endorsed by prominent exchange partners are perceived by investors as having better quality and are more likely to receive investments than firms without such endorsement (Stuart et al., 1999). Similarly, in crowdfunding contexts, Calic and Mosakowski (2016) found that third-party endorsements signal project quality and contribute to the success of crowdfunding.

Endorsements from third parties such as media websites, blogs and newspapers might influence the outcome of crowdfunding because the endorsements implicitly suggest that independent third parties have assessed the information concerning the venture and/or its product (Zuckerman, 1999). Hence, third-party endorsements can reduce the uncertainty in assessing and backing a crowdfunding project. Furthermore, third parties can serve as information intermediaries to convey information about the crowdfunding project. In line with this view, Calic and Mosakowski (2016) argue that, beyond signalling project quality, third-party endorsements can also enhance the exposure of crowdfunding projects. It is fair to expect that exposure from third parties might attract more people to search for and visit the project page. Consequently, projects endorsed by third parties can reach more audiences and thus have a higher chance of success in raising the funding.

Based on a scoping of the literature, the first stage of configurational theorising (Furnari et al., 2020), we 
develop an overarching framework (Fig. 1) that entails relevant signals that might form configurations to influence crowdfunding success. In particular, we argue that success experience, failure experience, backer experience and industry experience form a signal set that can help to signal entrepreneurs' credibility. This signal set entails experiences from crowdfunding and business domains. In addition, project preparedness and thirdparty endorsements form another signal set that can help to signal project quality. In the next session, we discuss how the interplay between the two signal sets might influence crowdfunding success, as well as the role signalling environments play in the signalling process.

\subsection{Developing the propositions: linking the signals}

The second stage of configurational theorising is linking (Furnari et al., 2020). That is, how the different signals connect with one another should be specified. We develop a set of propositions to outline how the different signals might work together to influence crowdfunding success. As discussed earlier, signals of entrepreneurs' credibility (success, failure, backer and industry experience) and project quality (preparedness and third-party endorsements) are likely to influence the outcome of crowdfunding. Whilst each of these signals might contribute to crowdfunding success in isolation, we argue that individual signals alone are not sufficient to achieve crowdfunding success. Since many crowdfunding projects might be in the early stage of development (Mollick, 2014), they tend to involve unfinished products or unproven market demand, meaning the crowd faces substantial uncertainty in selecting and backing a project. Furthermore, entrepreneurs possess more

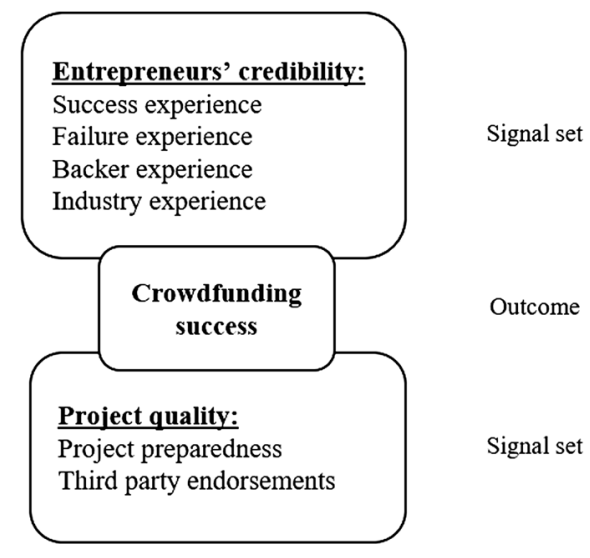

Fig. 1 The framework for analysis information about the prospect of the project as compared to the crowd (Davies \& Giovannetti, 2018). We reason that the signalling effect from one signal alone might not be strong enough to mitigate the information asymmetry and uncertainty in backing a project. Moreover, studies have highlighted that multiple signals often operate at the same time (Connelly et al., 2011; Plummer et al., 2016; Courtney et al., 2017; Drover et al., 2018; Bapna, 2019). In line with this view, we expect crowdfunding success might be a function of different signals working together. Hence, we posit that:

Proposition 1: Crowdfunding success requires multiple signals to work together such that the presence of one signal alone is not sufficient to produce crowdfunding success.

\subsubsection{The interplay of entrepreneurs' credibility and project quality for crowdfunding success}

Previous studies have provided useful insights about the signalling effects of entrepreneurs' credibility and project quality for crowdfunding success (Mollick, 2014; Courtney et al., 2017). Nevertheless, they represent only a partial picture as individual signals are examined in isolation. As such, the potential interplay between the different signals in affecting the outcome of crowdfunding is often ignored. Crowdfunding is a high-noise environment in which it is difficult to process signals in isolation. Instead, multiple signals compete with each other (Steigenberger \& Wilhelm, 2018). It is therefore important to consider the potential interplay among different signals because multiple signals often operate at the same time (Connelly et al., 2011; Courtney et al., 2017; Drover et al., 2018) and the effectiveness of one signal can depend on another signal (Plummer et al., 2016).

We therefore argue that it is critical to consider entrepreneurs' credibility and project quality signals in combination as they might work together to influence crowdfunding success in two important ways. On the one hand, they might complement each other to enhance crowdfunding process. Because crowdfunding experience signals entrepreneurs' credibility (Courtney et al., 2017; Davies \& Giovannetti, 2018) and project quality signal the viability of the project (Mollick, 2014; Calic \& Mosakowski, 2016), we reason they might reinforce each other to produce crowdfunding success. Supporting our view, evidence suggests the value of one signal (e.g. 
founders' managerial experience) is enhanced when another signal (e.g. affiliation with venture development organisations) is also present (Plummer et al., 2016).

On the other hand, entrepreneurs' credibility and project quality signals might substitute for each other to produce crowdfunding success. Due to the costs involved in the signalling process (Spence, 1973; Connelly et al., 2011), it might be too costly for entrepreneurs to leverage both credibility and quality signals simultaneously. Research into the investment decisions of venture capital investors suggests that a high-quality business concept can offset the failure experience of entrepreneurs (Cope et al., 2004). In line with this reasoning, we suspect quality enhancing signals such as preparedness and third-party endorsements might compensate entrepreneurs' lack of credibility. Similarly, the credibility of entrepreneurs might offset the lack of quality-enhancing signals. Indeed, previous research has shown that entrepreneurs' previous venture experience can lead to advantages in raising venture capital (Zhang, 2011). Accordingly, we posit that:

Proposition 2a: Signals of entrepreneurs' credibility and project quality can complement each other to produce crowdfunding success.

Signals of entrepreneurs' credibility can substitute absent project quality, and vice versa, to produce crowdfunding success.

\subsubsection{The role of signalling environments}

We argue that the effectiveness of signals for crowdfunding success depends not only on how they interact with each other but also the signalling environment. It is fair to expect that, in an environment with more uncertainty, stronger signals are required to mitigate the information asymmetry and perceived uncertainty in backing a project. The Indiegogo platform represents a signalling environment with more uncertainty as entrepreneurs who use a keep-it-all funding model can retain all contributions from the crowd irrespective of the campaign outcome (Cumming et al., 2019). The crowd might perceive Indiegogo projects as more risky as their contributions will be given to entrepreneurs even when the project is underfunded, which might consequently have a higher chance of failure in fulfilling the project (Cumming et al., 2019). Hence, we suspect, under an environment with more uncertainty (Indiegogo), both credibility and quality signals are required to produce crowdfunding success.
By contrast, in an environment with less uncertainty, the signals required to mitigate information asymmetry and establish legitimacy might be less demanding. The Kickstarter platform represents a signalling environment with less uncertainty as entrepreneurs can receive the contributions only when they meet the targeted funding goal (Mollick, 2014). When a project is under-funded, the contributions are returned to the crowd (Colombo et al., 2015). Since entrepreneurs are likely to pursue a project only when it is sufficiently funded, such projects should have a higher chance of success in fulfilling the rewards (Cumming et al., 2019). Other things being equal, the uncertainty perceived by the crowd should be lower for projects that are listed under Kickstarter than those listed under Indiegogo. We thus believe that, under an environment with less uncertainty (Kickstarter), the signals of either credibility or quality might be sufficient to produce crowdfunding success. Accordingly, we posit that:

Proposition 3a: Under an environment with more uncertainty, a combination of both entrepreneurs' credibility and project quality signals are necessary for crowdfunding success.

Under an environment with less uncertainty, signals of either entrepreneurs' credibility and/or project quality might be sufficient for crowdfunding success.

\section{Methodology}

To answer our research question, as well as to complete the final stage, naming, of the configurational theorising process (Furnari et al., 2020), we first need to conduct the analysis itself. We use the method of crisp-set qualitative comparative analysis (QCA) for several reasons. First, this method is based on a configurational perspective that allows us to identify configurations of causal conditions (i.e. signals of entrepreneurs' credibility and project quality) that can produce a specific outcome (i.e. crowdfunding success) (Ragin, 2008). Second, it can deal with causal equifinality meaning identifying multiple configurations that are effective in producing the same outcome (Fiss, 2007; Schneider \& Wagemann, 2012). Third, a crisp-set approach is appropriate because the outcome and causal conditions used in our study are all dichotomous variables (Ragin, 2008). Last, the QCA method has attracted 
increasing attention in entrepreneurship and management research (Greckhamer et al., 2018; Douglas et al., 2020).

\subsection{Sample and data collection}

We collected a unique dataset with 62 matched projects listed on both Kickstarter and Indiegogo. Kickstarter has been chosen because it is the world's largest reward-based crowdfunding platform (Mollick \& Nanda, 2015). It uses a funding model of all-or-nothing such that entrepreneurs can retain the contribution of funds from the crowds only if the project reaches its funding goal at the end of the campaign (Butticè et al., 2017). Indiegogo, another leading crowdfunding platform, offers the funding models of both all-or-nothing and keep-it-all. The latter means that entrepreneurs can retain all contribution of funds from the crowd even if the projects did not reach the funding goal (Cumming et al., 2019).

It is important to note that entrepreneurs might use crowdfunding to test the market (Mollick, 2014). A successful campaign allows entrepreneurs to demonstrate market demand that in turn might contribute to securing funds from other sources. Indeed, recent evidence from Bessière et al. (2020) has shown that reward-based crowdfunding can be the first step in a complex funding trajectory such that, after a successful campaign, firms then use other sources such as equity-based crowdfunding, business angels and venture capitals to raise funds. By contrast, an unsuccessful campaign might indicate a lack of market demand. Entrepreneurs can thus fail early or pivot to other project or venture ideas. Hence, we believe some of the projects used in our study might or might not turn into entrepreneurial ventures. Previous reward-based crowdfunding research from Giudici et al. (2018) has specifically identified entrepreneurial projects in their data, by excluding projects with non-profit based motivations. We did not apply this approach in our study due to the limited projects that are listed on two platforms.

We collected data from both Kickstarter and Indiegogo following several steps. First, we selected projects from Kickstarter under the "Technology and Design" category covering the launch date from 13 December 2013 to 21 June 2015 , leading to 1330 projects. The decision to focus on projects from one category is to enhance their comparability as projects from different categories might differ substantially due to their different nature. Second, we examine if any of the Kickstarter projects identified in the first step are also listed on Indiegogo. We identified 156 projects that are listed on both platforms using the same project title. Third, we manually examined the content of all campaign pages on both Kickstarter and Indiegogo. We found that 54 out of the 156 projects have to be removed due to issues such as the projects are different between Kickstarter and Indiegogo even though they share the same project title, some project pages are no longer available on the crowdfunding platforms, some projects have been suspended by Kickstarter or are under review at Indiegogo.

We then examined the funding model of Indiegogo projects as entrepreneurs have the option to choose between a keep-it-all or all-or-nothing funding model (Cumming et al., 2019). We found 27 projects use an all-or-nothing funding model and 75 projects use a keep-it-all funding model. To ensure the consistency of funding model used for all Indiegogo projects, we removed the 27 projects using an all-or-nothing funding model. This step allowed us to retain a sample of 75 matched projects that are listed on both Kickstarter and Indiegogo but with different funding models.

Research suggests many crowdfunding projects have a low funding goal that is under $\$ 1000$ (Mollick, 2014). Indeed, recent statistics from Kickstarter have shown that of the 194,320 successfully funded projects, $13 \%$ projects raised less than $\$ 1000,54 \%$ projects raised between $\$ 1000$ and $\$ 9999$ and 33\% projects raised above $\$ 10,000$ (Kickstarter, 2020). Because the majority (i.e. $87 \%$ ) of Kickstarter projects raised more than $\$ 1000$, we applied this threshold for the funding goal and removed 13 out of 75 projects from the dataset, leading to a final sample of 62 matched projects from both Kickstarter and Indiegogo. We believe setting the threshold can help reduce potential bias in our results because projects with low funding goals might have a higher chance to reach the funding target. To the best of our knowledge, the present study represents the first to adopt such an approach with matched samples from both platforms. This approach allows us to uncover how the effectiveness of signals for crowdfunding success for the same project might depend on the signalling environment.

\subsection{Measures and data calibration}

The QCA method starts with the procedure of data calibration. Because the outcome and causal conditions used in our study are all dichotomous variables, we coded the data as either 1 or 0 where 1 represents a full 
membership in the predefined group and 0 represents a full exclusion. In the following, we describe the measures and outline how the raw data is calibrated into set membership scores (i.e. 1 or 0 ).

\subsubsection{Outcome of interest}

Crowdfunding success Following previous studies (Calic \& Mosakowski, 2016; Courtney et al., 2017), we consider a Kickstarter project as successful if it achieves the target funding goal within the campaign duration. We coded the outcome as 1 if the project achieved funding equal to or above $100 \%$ of the funding goal (12 out of 62 Kickstarter projects). Otherwise, it was coded as 0 . We consider an Indiegogo project to be successful if it achieved a funding outcome that is above the mean value of the sample. Using the mean value ( $47.91 \%$ in our sample) as the cut-off point for Indiegogo projects is more appropriate given that entrepreneurs can retain all the funds they raised. Our cut-off point is higher than the mean completion ratio of $42 \%$ identified in recent research based on a sample of 21,650 Indiegogo projects using a keep-it-all funding model (Cumming et al., 2019). We coded the outcome of an Indiegogo project as 1 if it achieved a funding ratio equal or above the mean completion ratio ( 7 out of 62 Indiegogo projects). Otherwise, it was coded as 0.

\subsubsection{Causal conditions}

Signals of entrepreneurs' credibility We coded success experience and failure experience as 1 if the entrepreneur has succeeded or failed in launching at least one other project on the respective platform. They were coded as 0 if the entrepreneur had no such experience. We coded backer experience as 1 if the entrepreneur has backed at least one project of someone else. Otherwise, it was coded as 0 . Furthermore, we coded industry experience as 1 if the project description clearly showed that the project is in line with the industry experience of entrepreneurs. Otherwise, it was coded as 0 .

Signals of project quality Following Calic and Mosakowski (2016), we used the videos, images and texts that are included on a campaign page to capture project preparedness. Previous research has used the average of the counts of videos, images and words posted on the campaign page without considering the underlying differences between the different measures. To address this limitation, we applied $K$ - mean cluster analysis based on the number of seconds of videos, the number of images and the number of words in the project description to categorise projects into high preparedness, coded as 1 and low preparedness, coded as 0. Finally, we coded third-party endorsements as 1 if the project description indicated that the project is endorsed by independent third parties such as media websites, blogs and newspapers (Calic \& Mosakowski, 2016).

\subsection{QCA analysis}

The QCA method entails several steps (Schneider \& Wagemann, 2012). As discussed earlier, the first step is data calibration, meaning transforming the raw data into set membership scores - 1 or 0 in the present study. The second step in QCA analysis is necessity analysis - to assess whether any of the conditions are necessary for the outcome. The third step is sufficiency analysis - to assess the conditions that are sufficient to produce the outcome based on a truth table.

\subsubsection{Analysis of the necessary conditions}

Using fs/QCA 3.0 software (UC, 2017), we first conducted necessity analysis to assess whether the presence or absence $(\sim)$ of any of the individual signals concerning entrepreneurs' credibility (success, failure, backer and industry experience) and project quality (preparedness and third-party endorsements) were necessary for crowdfunding success. A signal is considered as a necessary condition for the result (i.e. crowdfunding success) if all cases exhibiting the result also exhibit the signal. Table 1 shows the results of the necessity analysis. The results suggest none of the conditions, except for backer experience (and then only for Kickstarter), was necessary to determine crowdfunding success for either Kickstarter or Indiegogo projects based on a consistency threshold of 0.9 (Schneider et al., 2010).

\subsubsection{Analysis of sufficient conditions}

We then performed a sufficiency analysis to identify the configurations that are sufficient to produce crowdfunding success. We first constructed a truth table consisting of 64 $\left(2^{6}\right)$ possible configurations based on the six causal conditions included in this study. After that, we removed configurations that contain no empirical cases. In line with the guidelines in QCA studies (Ragin, 2008), configurations that entail one empirical case is retained as the number of 
Table 1 Analysis of necessary conditions for crowdfunding success

\begin{tabular}{|c|c|c|c|c|}
\hline \multirow[t]{2}{*}{ Causal conditions } & \multicolumn{2}{|c|}{ Kickstarter projects } & \multicolumn{2}{|c|}{ Indiegogo projects } \\
\hline & Consistency & Coverage & Consistency & Coverage \\
\hline \multicolumn{5}{|c|}{ Signals of entrepreneurs' credibility } \\
\hline Success experience & 0.17 & 0.67 & 0.14 & 0.50 \\
\hline$\sim$ Success experience & 0.83 & 0.17 & 0.86 & 0.10 \\
\hline Failure experience & 0.33 & 0.44 & 0.14 & 0.14 \\
\hline$\sim$ Failure experience & 0.67 & 0.15 & 0.86 & 0.11 \\
\hline Backer experience & 0.92 & 0.46 & 0.43 & 0.23 \\
\hline$\sim$ Backer experience & 0.08 & 0.03 & 0.57 & 0.08 \\
\hline Industry experience & 0.67 & 0.31 & 0.71 & 0.20 \\
\hline Industry experience & 0.33 & 0.11 & 0.29 & 0.05 \\
\hline \multicolumn{5}{|l|}{ Signals of project quality } \\
\hline Project preparedness & 0.67 & 0.31 & 0.71 & 0.22 \\
\hline$\sim$ Project preparedness & 0.33 & 0.11 & 0.29 & 0.05 \\
\hline Third-party endorsements & 0.42 & 0.50 & 0.71 & 0.50 \\
\hline Third-party endorsements & 0.58 & 0.13 & 0.29 & 0.04 \\
\hline
\end{tabular}

Note: indicates the absence of the causal condition

matched projects is not large. Third, we coded the outcome of the individual configurations as 1 if the consistency, which refers to "the degree to which instances of an outcome agree in displaying the causal condition" (Ragin, 2008, p. 44), is equal or above the threshold of 0.75 . The remaining configurations were coded as 0 . The truth tables for Kickstarter (Table 3) and Indiegogo projects (Table 4) are shown in Appendix 1. Each row of the truth table represents one of the combinations or configurations of conditions that is associated with the outcome. Finally, we used the fs/QCA 3.0 software to derive solutions based on the Quine-McCluskey algorithm (Fiss, 2007; UC, 2017). The model used in our sufficiency analysis contains six conditions:

Crowdfunding success $=\mathrm{f}$ (success experience, failure experience, backer experience, industry experience, project preparedness, third-party endorsements)

The QCA method provides three types of solutions (i.e. complex, intermediate and parsimonious solutions) depending on whether and how configurations with no empirical cases (called "logical remainders" or "counterfactuals) are included in the analysis. We make no directional assumptions on the logical remainders due to lack of empirical evidence and theoretical knowledge. Furthermore, researchers have devoted limited attention to how the signals might work together to influence crowdfunding success. Therefore, our results are reported based on "complex" solutions, also known as "conservative" solutions as configurations with no empirical cases or logical remainders are not included in the analysis (Schneider \& Wagemann, 2012).

\section{Findings}

\subsection{Results from sufficiency analysis}

Table 2 shows the results from sufficiency analysis. As shown in the table, five configurations (K1 to K5) are sufficient to produce crowdfunding success for Kickstarter projects and another two configurations (D1 and D2) can lead to crowdfunding success for Indiegogo projects. The consistency for all individual configurations and the overall solutions were above the threshold of 0.75 for both Kickstarter and Indiegogo projects (Ragin, 2008). This means the outcome - crowdfunding success - is consistently explained by the configurations identified in our study. Furthermore, the overall solution coverages of 0.42 for Kickstarter projects and 0.29 for Indiegogo projects suggest a substantial proportion of the outcome are explained by the configurations.

For Kickstarter projects, configuration K1 implies that joint presence of failure experience and backer experience can lead to crowdfunding success when all 
Table 2 Analysis of sufficient conditions for crowdfunding success

\begin{tabular}{|c|c|c|c|c|c|c|c|}
\hline \multirow[t]{2}{*}{ Causal conditions } & \multicolumn{5}{|c|}{ Kickstarter projects } & \multicolumn{2}{|c|}{ Indiegogo projects } \\
\hline & $\mathrm{K} 1$ & $\mathrm{~K} 2$ & $\mathrm{~K} 3$ & K4 & K5 & D1 & D2 \\
\hline \multicolumn{8}{|c|}{ Signals of entrepreneurs' credibility } \\
\hline Success experience & $\circ$ & $\bullet$ & $\circ$ & ० & $\bullet$ & $\circ$ & $\circ$ \\
\hline Failure experience & $\bullet$ & ० & $\bullet$ & $\bullet$ & $\bullet$ & ० & $\circ$ \\
\hline Backer experience & $\bullet$ & $\bullet$ & $\bullet$ & $\bullet$ & $\bullet$ & $\bullet$ & $\bullet$ \\
\hline Industry experience & ० & $\bullet$ & $\bullet$ & ० & $\bullet$ & ० & $\bullet$ \\
\hline \multicolumn{8}{|l|}{ Signals of project quality } \\
\hline Project preparedness & $\circ$ & $\bullet$ & $\bullet$ & $\bullet$ & ○ & $\circ$ & $\bullet$ \\
\hline Third-party endorsement & ० & ० & ० & $\bullet$ & $\bullet$ & $\bullet$ & - \\
\hline Consistency & 1 & 1 & 1 & 1 & 1 & 1 & 1 \\
\hline Raw coverage & 0.08 & 0.08 & 0.08 & 0.08 & 0.08 & 0.14 & 0.14 \\
\hline Unique coverage & 0.08 & 0.08 & 0.08 & 0.08 & 0.08 & 0.14 & 0.14 \\
\hline Overall solution consistency & 1 & & & & & 1 & \\
\hline Overall solution coverage & 0.42 & & & & & 0.29 & \\
\hline
\end{tabular}

Note: $\bullet(\circ)$ represents the presence (absence) of the causal condition

other conditions are absent. Configuration $\mathrm{K} 2$ shows that joint presence of success experience, backer experience, industry experience and project preparedness is sufficient to produce crowdfunding success when failure experience and third-party endorsements are absent. In contrast to configuration $\mathrm{K} 2$, configuration $\mathrm{K} 3$ entails absent success experience and the presence of failure experience. Configuration K4 suggests failure experience, backer experience in combination with project preparedness and third-party endorsements is sufficient to produce crowdfunding success when other signals are absent. Finally, configuration K5 suggests the presence of all signals except project preparedness can lead to crowdfunding success.

For Indiegogo projects, configuration D1 implies backer experience in combination with third-party endorsements can produce crowdfunding success when other signals are absent. Configuration D2 shows that joint presence of backer experience, industry experience, project preparedness and third-party endorsements are sufficient for crowdfunding success when other signals are absent.

\subsection{Robustness checks}

To scrutinise the results, we performed a series of robustness checks by (a) changing consistency thresholds, (b) changing calibration thresholds for the outcome and (c) analysing conditions for absence of the outcome, following An et al. (2020). First, we changed consistency thresholds for sufficiency analysis from 0.75 to 0.9 , a more stringent level, for both Kickstarter and Indiegogo projects. The resulting solutions for both Kickstarter and Indiegogo projects are all identical to our baseline results shown in Table 2.

Second, we changed calibration thresholds for the crowdfunding outcome of Indiegogo projects from the mean value to equal or above $80 \%$ of the funding goal. As Cumming et al. (2019) pointed out, a completion ratio of $80 \%$ can be considered as extended success because it is almost complete for keep-it-all projects. We first coded the crowdfunding outcome as 1 if the Indiegogo project achieved funding equal or above $80 \%$ of the funding goal (6 out of 62 Indiegogo projects). Otherwise, it was coded as 0 . We then performed the sufficiency analysis for Indiegogo projects. The results from this analysis show that two configurations are sufficient to produce crowdfunding success with a solution coverage of 0.33 and a solution consistency of 1 . The two configurations identified from the robustness test are identical to the configurations D1 and D2 from our baseline results shown in Table 2.

As a final step, we also conducted a sufficiency analysis to identify conditions that are sufficient to produce the absence of the outcome. The results for the absence of crowdfunding success are shown in Appendix 2, Table 5 for Kickstarter projects and Table 6 for Indiegogo projects. 
As shown in the two tables, the overall solution consistency are all above the recommended threshold of 0.75 (Ragin, 2008) and all resulting configurations are distinct from our main results presented in Table 2, meaning the absence of contradictory solutions between the presence and absence of the outcome. The results for the absence of crowdfunding success thus provide further support for our main findings.

\section{Discussion, contributions, limitations and future research}

\subsection{Discussion: naming}

Our empirical findings reveal that whilst individual signals alone are important, they are not sufficient to produce crowdfunding success. Configurations K1 to K5 and configurations D1 and D2 suggest crowdfunding success requires the presence of at least two signals to work together, supporting proposition 1. Since crowdfunding involves information asymmetry, entrepreneurs often need to rely on observable signals to demonstrate project potential and mitigate the crowd's perceived risk in backing a project (Davies \& Giovannetti, 2018; Colombo, 2020). Our results demonstrate that the signalling effect from one signal alone is not sufficient to convey the project potential and produce crowdfunding success.

On this basis, we have identified and named two overarching configurational patterns - the naming stage of configurational theorising (Furnari et al., 2020) - that capture how signals can interact to generate legitimacy and in turn crowdfunding success:

- Success based on the entrepreneurs' credibility only (K1): "Investing in the entrepreneur"

- Success based on a combination of the entrepreneurs' credibility and project quality (K2 to K5 and D1 and D2): "Investing in the package"

Consistent with proposition 2a, we found that signals of credibility and project quality complement each other to produce crowdfunding success. Configurations K2 to K5 and configurations D1 and D2, for example, all entail the presence of both types of signals. Our findings also show that credibility can compensate for absent project quality (K1), to produce crowdfunding success. This finding provides partial support for proposition $2 b$ because none of the configurations indicates project quality can compensate for absent credibility. Previous research has shown the importance of crowdfunding experience and project quality for crowdfunding success (Courtney et al., 2017; Davies \& Giovannetti, 2018). We expand prior works by uncovering the interplay between the two types of signals in shaping crowdfunding success. Our results support recent work suggesting the effectiveness of one signal depends on the presence of another signal (Plummer et al., 2016). More importantly, we show that lack of project quality will not necessarily hinder crowdfunding success as it can be offset by the presence of credibility. These results suggest the effectiveness of signals for crowdfunding success depends on their configurations.

A comparison between the configurations for Kickstarter and Indiegogo projects shows that the effectiveness of signals for crowdfunding success also depends on the signalling environment. Supporting proposition 3a, configurations D1 and D2 suggest that under an environment with more uncertainty (Indiegogo), a combination of both entrepreneurs' credibility and project quality are required for crowdfunding success. Our results provide partial support for proposition $3 \mathrm{~b}$ suggesting that signals of entrepreneurs' credibility (K1) alone, but not project quality, are sufficient to produce crowdfunding success under an environment with less uncertainty (Kickstarter). These results indicate that stronger signals are required for entrepreneurs to mitigate information asymmetry and thus achieve crowdfunding success under an environment with more uncertainty.

\subsection{Contributions}

Our study contributes to the extant literature in several ways. First, we contribute to research on the role of signalling in entrepreneurial finance in general and rewardbased crowdfunding in particular (Colombo, 2020), through conducting cross-platform analysis that takes into account the different signalling required in environments with different levels of uncertainty. Specifically, we expand crowdfunding research based on signalling theory by using a sample of matched projects that are listed on two different platforms. In doing so, we provide evidence showing how the effectiveness of signals for crowdfunding success depends on the signalling environment. Our findings address calls to consider the role of signalling environment in the signalling process for gaining entrepreneurial finance (Connelly et al., 2011; Colombo, 2020), as well as how different contexts of crowdfunding might influence funding outcomes (McKenny et al., 2017). Based on our 
findings, we argue the platforms' funding model is an important environment-related boundary condition that impacts the effectiveness of signal sets (Colombo, 2020). For funding models that provide more certainty (such as Kickstarter), signalling credibility can establish sufficient legitimacy for the crowd to invest. On platforms with more uncertain funding models credibility and project quality signals are only effective in combination with each other. These findings point to the importance of understanding the boundary conditions of signalling, an aspect currently not sufficiently addressed in traditional signalling theory.

Second, although previous studies have considered the role of credibility and project quality for crowdfunding success (Mollick, 2014; Courtney et al., 2017), the potential interplay between different signals is underexplored. We extended this line of research by examining how the interplay of multiple signals influences the outcome of crowdfunding. Exploring combinations of signals or signal sets is particularly relevant in high-noise environments such as crowdfunding where multiple signals compete for the attention of the crowd and bundling signals into sets is more effective (Colombo, 2020; Drover et al., 2018; Steigenberger \& Wilhelm, 2018). We uncover that different signals can complement each other to produce crowdfunding success, and the presence of certain signals (e.g. credibility) can compensate for the absence of others (e.g. project quality). Our contribution is important as it provides evidence showing the importance of considering the signal sets in accessing entrepreneurial finance as the signals are likely to work in combination, rather than operating independently from each other. As such, this study addresses recent calls to capture "simultaneous interactions of multiple signals" rather than capturing signals in isolation, particularly for the study of legitimacy (Drover et al., 2018, p. 225). By adopting a configurational approach using QCA, we are able to shed light on how different signals relating to the entrepreneur and the project work together to produce crowdfunding success. We not only identify multiple configurations that can produce the same outcome but also summarise them into two overarching patterns that explain the complex phenomenon of crowdfunding success in a more meaningful way (Furnari et al., 2020). Our study builds on the work of Colombo et al. (2019), albeit using a different method, showing that different sets of multiple signals, conveying different information from one another, can create positive outcomes.

Third, in contrast to previous research suggesting failure experience negatively impacts the likelihood of crowdfunding success (Butticè et al., 2017), we found that four out of seven configurations (i.e. K1, K3, K4, $\mathrm{K} 5$ ) leading to crowdfunding success entailed failure experience. Interestingly, in most of the configurations, failure and success experience substituted each other, whilst in only one configuration, they complemented each other (K5). Different explanations are put forward for substitution and complementary effects. First, in the context of new venture creation, novice entrepreneurs are lacking a track record of success. The signal of failure experience allows them to demonstrate a track record of learning that can often lead to the development of knowledge and skills (Cope \& Watts, 2000), which in turn prepares entrepreneurs to launch a better new project. The failure experience signal can thus substitute for the lack of success experience. Second, because of the high failure rate in crowdfunding, the predominance of failure experiences in the configurations combined with some success experiences represent a more realistic picture of the challenges to obtain crowdfunding success. Overall, our findings suggest that failure experience will not necessarily hamper crowdfunding success. On the contrary, failure experience can substitute for the lack of prior success experience or complement success experience to produce a more realistic picture of the entrepreneurs. This implies that examining individual failure and success signals in isolation may conceal their actual effect on the outcome of crowdfunding.

Our study also offers important practical implications for entrepreneurs on how to leverage different signals for gaining entrepreneurial finance in the setting of reward-based crowdfunding. In the situation of absent project quality, entrepreneurs can leverage their credibility by emphasising their previous experience in creating and backing crowdfunding projects. To signal credibility, backer experience featured most prominently amongst all configurations. Similarly, project preparedness also featured frequently as a signal for quality. Both of these conditions are, however, under the control of the entrepreneur and well worth considering investing effort into. Specifically, being part of the crowdfunding community as a backer and investing time and effort to preparing the campaign using videos, images and texts (Colombo et al., 2015; Calic \& Mosakowski, 2016) are important signals to establish legitimacy. Lastly, carefully considering the platform through which to crowdfund is important as the funding model impacts on the effectiveness of signals. 


\subsection{Limitations and future research}

Our study has some limitations that present opportunities for further research. First, we applied QCA to capture the potential causal complexity between the different signals and crowdfunding success (Ragin, 2008; Greckhamer, 2016), and are hence unable to measure the ultimate degree of success of the project as Colombo et al. (2019) were able to do. The QCA method can extend crowdfunding research based on signalling theory by uncovering how multiple signals work in combinations to influence the outcome of crowdfunding. Conversely, this study only captures the presence or absence of a signal without distinguishing the extent of the signal. The number of previous successful or failure projects may also influence how the crowd perceive the signal. To illustrate, entrepreneurs who experienced several failures without any success might be perceived as a lack of skills (Hochberg et al., 2014). Future research efforts might take into account the extent of the individual signals to develop a more refined understanding of their signalling effects for crowdfunding success.

Second, we limited our sample to projects within one single category from reward-based crowdfunding platforms. This allows us to match projects across Kickstarter and Indiegogo and manually verify the consistency of projects that are listed on both platforms. In so doing, we offer insights about how the effectiveness of signals depends on the signalling environment. It is unclear, however, whether our results hold for projects that are from other categories or projects that are from other forms of entrepreneurial finance such as the equity-based, debt-based or donation-based crowdfunding (McKenny et al., 2017; Block et al., 2018). Future studies might scrutinise our findings by examining projects from other categories, as well as projects from other forms of entrepreneurial finance.

Finally, whilst the present study provides useful insights about the role of signalling for crowdfunding success, one important component in the signalling process - signal receiver - has not received sufficient attention (Colombo, 2020). We believe the effectiveness of signals might also depend on the motives, experiences and backgrounds of the signal receiver. For example, recent research in equitybased crowdfunding has distinguished professional/ qualified investors from restricted investors who are less experienced (Signori \& Vismara, 2018; Vismara, 2019). More importantly, research suggests that investors are motivated by different logics (e.g. market logic and community logic) in making investment decisions (Vismara,
2019). Hence, it is fair to expect that investors, as signal receivers, might react to the same signal differently when their underlying motivations for investments are distinct. Furthermore, individuals (i.e. returning backers) who have supported previous projects from entrepreneurs might have an information advantage over first-time backers about the skills of the entrepreneurs. Hence, they might perceive the same signal differently from first-time backers. In addition, signal receivers also differ in their attitude toward risktaking. All else equal, the signals required for crowdfunding success might need to be stronger for backers who are more risk-averse (Petitjean, 2018). Future research could explore how the signalling effect for crowdfunding success might depend on the characteristics of signal receivers.

\section{Conclusions}

In recent years, entrepreneurs have increasingly turned to the crowd to fund projects. Crowdfunding, however, involves information asymmetry and entrepreneurs often need to rely on observable signals to demonstrate the potential of their projects. Building on signalling theory, the present study sheds new light on how entrepreneur credibility and project quality signals work together to produce crowdfunding success under different signalling environments. Based on a configurational approach using QCA, we show that the effectiveness of signals for crowdfunding success depends on their configurations, as well as the signalling environment. We hope this study will inspire further research on entrepreneurial finance to consider signal combinations as our evidence shows that multiple signals are likely to work together to influence the outcome of crowdfunding.

Availability of data and material The datasets generated during and/or analysed during the current study are available from the corresponding author on reasonable request.

Code availability Not applicable.

\section{Declarations}

Conflict of interest The authors declare no competing interests. 


\section{Appendix}

\section{Appendix 1 Truth tables}

Table 3 Truth table for Kickstarter projects

\begin{tabular}{lllllllll}
\hline Rows & Conditions & & & & & & \\
\cline { 2 - 8 } & $\begin{array}{l}\text { Success } \\
\text { experience }\end{array}$ & $\begin{array}{l}\text { Failure } \\
\text { experience }\end{array}$ & $\begin{array}{l}\text { Backer } \\
\text { experience }\end{array}$ & $\begin{array}{l}\text { Industry } \\
\text { experience }\end{array}$ & $\begin{array}{l}\text { Project } \\
\text { preparedness }\end{array}$ & $\begin{array}{l}\text { Third-party } \\
\text { endorsements }\end{array}$ & $\begin{array}{l}\text { Number of } \\
\text { cases }\end{array}$ & $\begin{array}{l}\text { Crowdfunding } \\
\text { success }\end{array}$ \\
\hline 1 & 0 & 1 & 1 & 0 & 0 & 0 & 1 & 1 \\
2 & 1 & 0 & 1 & 1 & 1 & 0 & 1 & 1 \\
3 & 0 & 1 & 1 & 1 & 1 & 0 & 1 & 1 \\
4 & 1 & 1 & 1 & 1 & 0 & 1 & 1 & 1 \\
5 & 0 & 1 & 1 & 0 & 1 & 1 & 1 & 1 \\
6 & 0 & 0 & 1 & 1 & 1 & 1 & 3 & 0 \\
7 & 0 & 0 & 1 & 1 & 1 & 0 & 2 & 0 \\
8 & 0 & 0 & 1 & 0 & 1 & 1 & 2 & 0 \\
9 & 0 & 0 & 1 & 0 & 1 & 0 & 3 & 0 \\
10 & 0 & 0 & 1 & 1 & 0 & 0 & 4 & 0 \\
11 & 0 & 0 & 0 & 1 & 0 & 0 & 5 & 0 \\
12 & 0 & 0 & 0 & 0 & 0 & 0 & 17 & 0 \\
13 & 0 & 0 & 0 & 1 & 1 & 0 & 7 & 0 \\
14 & 0 & 0 & 1 & 0 & 0 & 0 & 4 & 0 \\
15 & 0 & 0 & 0 & 0 & 1 & 0 & 3 & 0 \\
16 & 0 & 1 & 0 & 0 & 0 & 0 & 2 & 0 \\
17 & 1 & 1 & 0 & 0 & 0 & 0 & 1 & 0 \\
18 & 0 & 1 & 0 & 1 & 1 & 0 & 1 & 0 \\
19 & 0 & 0 & 0 & 0 & 0 & 1 & 1 & 0 \\
20 & 0 & 0 & 0 & 0 & 1 & 1 & 1 & 0 \\
21 & 0 & 1 & 1 & 1 & 1 & 1 & 1 \\
\hline
\end{tabular}

Note 1: 43 rows contain no empirical case are not displayed in the truth table

Note 2: 0 represents non-membership in the set; 1 represents full membership in the set 
Table 4 Truth table for Indiegogo projects

\begin{tabular}{|c|c|c|c|c|c|c|c|c|}
\hline \multirow[t]{2}{*}{ Rows } & \multicolumn{8}{|l|}{ Conditions } \\
\hline & $\begin{array}{l}\text { Success } \\
\text { experience }\end{array}$ & $\begin{array}{l}\text { Failure } \\
\text { experience }\end{array}$ & $\begin{array}{l}\text { Backer } \\
\text { experience }\end{array}$ & $\begin{array}{l}\text { Industry } \\
\text { experience }\end{array}$ & $\begin{array}{l}\text { Project } \\
\text { preparedness }\end{array}$ & $\begin{array}{l}\text { Third-party } \\
\text { endorsements }\end{array}$ & $\begin{array}{l}\text { Number of } \\
\text { cases }\end{array}$ & $\begin{array}{l}\text { Crowdfunding } \\
\text { success }\end{array}$ \\
\hline 1 & 0 & 0 & 1 & 0 & 0 & 1 & 1 & 1 \\
\hline 2 & 0 & 0 & 1 & 1 & 1 & 1 & 1 & 1 \\
\hline 3 & 1 & 1 & 1 & 1 & 0 & 1 & 2 & 0 \\
\hline 4 & 0 & 0 & 0 & 0 & 1 & 1 & 2 & 0 \\
\hline 5 & 0 & 0 & 0 & 1 & 1 & 1 & 2 & 0 \\
\hline 6 & 0 & 0 & 0 & 1 & 1 & 0 & 6 & 0 \\
\hline 7 & 0 & 0 & 0 & 0 & 0 & 0 & 20 & 0 \\
\hline 8 & 0 & 0 & 0 & 1 & 0 & 0 & 7 & 0 \\
\hline 9 & 0 & 0 & 0 & 0 & 1 & 0 & 7 & 0 \\
\hline 10 & 0 & 1 & 0 & 0 & 0 & 0 & 3 & 0 \\
\hline 11 & 0 & 0 & 1 & 1 & 1 & 0 & 3 & 0 \\
\hline 12 & 0 & 0 & 1 & 1 & 0 & 0 & 2 & 0 \\
\hline 13 & 0 & 0 & 1 & 0 & 1 & 0 & 2 & 0 \\
\hline 14 & 0 & 0 & 1 & 0 & 0 & 0 & 1 & 0 \\
\hline 15 & 0 & 1 & 1 & 1 & 0 & 0 & 1 & 0 \\
\hline 16 & 0 & 0 & 0 & 0 & 0 & 1 & 1 & 0 \\
\hline 17 & 0 & 1 & 0 & 1 & 0 & 1 & 1 & 0 \\
\hline
\end{tabular}

Note 1: 41 rows contain no empirical case are not displayed in the truth table

Note 2: 0 represents non-membership in the set; 1 represents full membership in the set

Appendix 2 Robustness test

Table 5 Analysis of sufficient conditions for the absence of crowdfunding success (Kickstarter projects)

\begin{tabular}{|c|c|c|c|c|c|}
\hline Causal conditions & AK1 & $\mathrm{AK} 2$ & $\mathrm{AK} 3$ & $\mathrm{AK} 4$ & AK5 \\
\hline \multicolumn{6}{|c|}{ Signals of entrepreneurs' credibility } \\
\hline Success experience & $\circ$ & $\circ$ & & $\circ$ & $\circ$ \\
\hline Failure experience & $\circ$ & $\circ$ & $\bullet$ & & $\bullet$ \\
\hline Backer experience & & $\circ$ & $\circ$ & $\circ$ & $\bullet$ \\
\hline Industry experience & & $\circ$ & $\circ$ & $\bullet$ & $\bullet$ \\
\hline \multicolumn{6}{|l|}{ Signals of project quality } \\
\hline Project preparedness & $\circ$ & & $\circ$ & $\bullet$ & $\bullet$ \\
\hline Third-party endorsement & $\circ$ & & $\circ$ & $\circ$ & $\bullet$ \\
\hline Consistency & 0.93 & 1.00 & 1.00 & 1.00 & 1.00 \\
\hline Raw coverage & 0.56 & 0.44 & 0.06 & 0.16 & 0.02 \\
\hline Unique coverage & 0.22 & 0.10 & 0.06 & 0.16 & 0.02 \\
\hline Overall solution consistency & 0.96 & & & & \\
\hline Overall solution coverage & 0.90 & & & & \\
\hline
\end{tabular}

Note: $\bullet(\circ)$ represents the presence (absence) of the causal condition; a blank space indicates the condition is irrelevant 
Table 6 Analysis of sufficient conditions for the absence of crowdfunding success (Indiegogo projects)

\begin{tabular}{|c|c|c|c|c|c|c|c|}
\hline Causal conditions & AD1 & $\mathrm{AD} 2$ & AD3 & AD4 & AD5 & AD6 & AD7 \\
\hline \multicolumn{8}{|c|}{ Signals of entrepreneurs' credibility } \\
\hline Success experience & $\circ$ & $\circ$ & $\circ$ & $\circ$ & $\circ$ & $\circ$ & $\circ$ \\
\hline Failure experience & $\circ$ & $\circ$ & $\circ$ & $\circ$ & $\circ$ & & $\bullet$ \\
\hline Backer experience & & $\circ$ & $\bullet$ & & $\circ$ & $\bullet$ & $\circ$ \\
\hline Industry experience & & & & $\circ$ & $\circ$ & $\bullet$ & $\bullet$ \\
\hline \multicolumn{8}{|l|}{ Signals of project quality } \\
\hline Project preparedness & $\circ$ & & & ० & $\circ$ & $\circ$ & $\circ$ \\
\hline Third-party endorsement & $\circ$ & $\circ$ & $\circ$ & $\circ$ & & $\circ$ & $\bullet$ \\
\hline Consistency & 1.00 & 1.00 & 1.00 & 1.00 & 1.00 & 1.00 & 0.02 \\
\hline Raw coverage & 0.55 & 0.55 & 0.15 & 0.42 & 0.38 & 0.05 & 0.02 \\
\hline Unique coverage & 0.13 & 0.13 & 0.05 & 0.05 & 0.02 & 0.02 & 1.00 \\
\hline Overall solution consistency & 1.00 & & & & & & \\
\hline Overall solution coverage & 0.87 & & & & & & \\
\hline
\end{tabular}

Note: $\bullet(\circ)$ represents the presence (absence) of the causal condition; a blank space indicates the condition is irrelevant

Open Access This article is licensed under a Creative Commons Attribution 4.0 International License, which permits use, sharing, adaptation, distribution and reproduction in any medium or format, as long as you give appropriate credit to the original author(s) and the source, provide a link to the Creative Commons licence, and indicate if changes were made. The images or other third party material in this article are included in the article's Creative Commons licence, unless indicated otherwise in a credit line to the material. If material is not included in the article's Creative Commons licence and your intended use is not permitted by statutory regulation or exceeds the permitted use, you will need to obtain permission directly from the copyright holder. To view a copy of this licence, visit http://creativecommons.org/licenses/by/4.0/.

\section{References}

Aaker, J. L., \& Akutsu, S. (2009). Why do people give? The role of identity in giving. Journal of consumer psychology, 19(3), 267-270.

Ahlers, G. K. C., Cumming, D., Günther, C., \& Schweizer, D. (2015). Signaling in equity crowdfunding. Entrepreneurship Theory and Practice, 39(4), 955-980.

An, W., Rüling, C.-C., Zheng, X., \& Zhang, J. (2020). Configurations of effectuation, causation, and bricolage: Implications for firm growth paths. Small Business Economics, 54(3), 843-864.

Anglin, A. H., Short, J. C., Drover, W., Stevenson, R. M., McKenny, A. F., \& Allison, T. H. (2018). The power of positivity? The influence of positive psychological capital language on crowdfunding performance. Journal of Business Venturing, 33(4), 470-492.

Bapna, S. (2019). Complementarity of signals in early-stage equity investment decisions: Evidence from a randomized field experiment. Management Science, 65(2), 933-952.
Behrens, J., Patzelt, H., Schweizer, L., \& Bürger, R. (2012). Specific managerial human capital, firm age, and venture capital financing of biopharmaceutical ventures: A contingency approach. The Journal of High Technology Management Research, 23(2), 112-121.

Bessière, V., Stéphany, E., \& Wirtz, P. (2020). Crowdfunding, business angels, and venture capital: An exploratory study of the concept of the funding trajectory. Venture Capital, 22(2), 135-160.

Bi, S., Liu, Z., \& Usman, K. (2017). The influence of online information on investing decisions of reward-based crowdfunding. Journal of Business Research, 71, 10-18.

Block, J. H., Colombo, M. G., Cumming, D. J., \& Vismara, S. (2018). New players in entrepreneurial finance and why they are there. Small Business Economics, 50(2), 239-250.

Bollaert, H., Leboeuf, G., \& Schwienbacher, A. (2020). The narcissism of crowdfunding entrepreneurs. Small Business Economics, 55(1), 57-76.

Butticè, V., Colombo, M. G., \& Wright, M. (2017). Serial crowdfunding, social capital, and project success. Entrepreneurship Theory and Practice, 41(2), 183-207.

Calic, G., \& Mosakowski, E. (2016). Kicking off social entrepreneurship: How a sustainability orientation influences crowdfunding success: Kicking off social entrepreneurship. Journal of Management Studies, 53(5), 738-767.

Cappa, F., Pinelli, M., Maiolini, R., \& Leone, M. I. (2020). "Pledge" me your ears! The role of narratives and narrator experience in explaining crowdfunding success. Small Business Economics. https://doi.org/10.1007/s11187-020-00334-y.

Cassar, G. (2006). Entrepreneur opportunity costs and intended venture growth. Journal of Business Venturing, 21(5), 610-632.

Chen, X.-P., Yao, X., \& Kotha, S. (2009). Entrepreneur passion and preparedness in business plan presentations: A persuasion analysis of venture capitalists' funding decisions. Academy of Management Journal, 52(1), 199-214.

Coleman, J. S. (1988). Social capital in the creation of human capital. American Journal of Sociology, 94, S95-S120. 
Colombo, O. (2020). The use of signals in new-venture financing: A review and research agenda. Journal of Management. https://doi.org/10.1177/0149206320911090.

Colombo, M. G., Franzoni, C., \& Rossi-Lamastra, C. (2015). Internal social capital and the attraction of early contributions in crowdfunding. Entrepreneurship Theory and Practice, 39(1), 75-100.

Colombo, M. G., Meoli, M., \& Vismara, S. (2019). Signaling in science-based IPOs: The combined effect of affiliation with prestigious universities, underwriters, and venture capitalists. Journal of Business Venturing, 34(1), 141-177.

Connelly, B. L., Certo, S. T., Ireland, R. D., \& Reutzel, C. R. (2011). Signaling theory: A review and assessment. Journal of Management, 37(1), 39-67.

Cope, J. (2011). Entrepreneurial learning from failure: An interpretative phenomenological analysis. Journal of Business Venturing, 26(6), 604-623.

Cope, J., \& Watts, G. (2000). Learning by doing-an exploration of experience, critical incidents and reflection in entrepreneurial learning. International Journal of Entrepreneurial Behaviour \& Research, 6(3), 104-124.

Cope, J., Cave, F., \& Eccles, S. (2004). Attitudes of venture capital investors towards entrepreneurs with previous business failure. Venture Capital, 6(2-3), 147-172.

Courtney, C., Dutta, S., \& Li, Y. (2017). Resolving information asymmetry: Signaling, endorsement, and crowdfunding success. Entrepreneurship Theory and Practice, 41(2), 265-290.

Crowdcube. (2020). Crowdcube: Funding the wonderful. https://www.crowdcube.com/explore/investing. Accessed 28 December 2020

Cumming, D. J., Leboeuf, G., \& Schwienbacher, A. (2019). Crowdfunding models: Keep-it-all vs. all-or-nothing. Financial Management. https://doi.org/10.1111/fima.12262.

Davies, W. E., \& Giovannetti, E. (2018). Signalling experience \& reciprocity to temper asymmetric information in crowdfunding evidence from 10,000 projects. Technological Forecasting and Social Change, 133, 118-131.

Delmar, F., \& Shane, S. (2006). Does experience matter? The effect of founding team experience on the survival and sales of newly founded ventures. Strategic Organization, 4(3), 215-247.

Di Pietro, F., Grilli, L., \& Masciarelli, F. (2020). Talking about a revolution? Costly and costless signals and the role of innovativeness in equity crowdfunding. Journal of Small Business Management, 1-32.

Dimov, D. (2010). Nascent entrepreneurs and venture emergence: Opportunity confidence, human capital, and early planning. Journal of Management Studies, 47(6), 1123-1153.

Douglas, E. J., Shepherd, D. A., \& Prentice, C. (2020). Using fuzzy-set qualitative comparative analysis for a finer-grained understanding of entrepreneurship. Journal of Business Venturing, 35(1), 105970.

Drover, W., Wood, M. S., \& Corbett, A. C. (2018). Toward a cognitive view of signalling theory: Individual attention and signal set interpretation. Journal of Management Studies, 55(2), 209-231.

Fiss, P. C. (2007). A set-theoretic approach to organizational configurations. Academy of Management Review, 32(4), 1180-1198.

Frydrych, D., Bock, A. J., Kinder, T., \& Koeck, B. (2014). Exploring entrepreneurial legitimacy in reward-based crowdfunding. Venture Capital, 16(3), 247-269.
Furnari, S., Crilly, D., Misangyi, V. F., Greckhamer, T., Fiss, P. C., \& Aguilera, R. (2020). Capturing causal complexity: Heuristics for configurational theorizing. Academy of Management Review, amr.2019.0298. https://doi. org/10.5465/amr.2019.0298.

Gaskill, L. R., Van Auken, H. E., \& Manning, R. A. (1993). A factor analytic study of the perceived causes of small business failure. Journal of small business management, 31, 18-18.

Ghatak, M., Morelli, M., \& Sjöström, T. (2007). Entrepreneurial talent, occupational choice, and trickle up policies. Journal of Economic Theory, 137(1), 27-48.

Giudici, G., Guerini, M., \& Rossi-Lamastra, C. (2018). Rewardbased crowdfunding of entrepreneurial projects: The effect of local altruism and localized social capital on proponents' success. Small Business Economics, 50(2), 307-324.

Greckhamer, T. (2016). CEO compensation in relation to worker compensation across countries: The configurational impact of country-level institutions. Strategic Management Journal, 37(4), 793-815.

Greckhamer, T., Furnari, S., Fiss, P. C., \& Aguilera, R. V. (2018). Studying configurations with qualitative comparative analysis: Best practices in strategy and organization research. Strategic Organization, 16(4), 482-495.

Hochberg, Y. V., Ljungqvist, A., \& Vissing-Jørgensen, A. (2014). Informational holdup and performance persistence in venture capital. Review of Financial Studies, 27(1), 102-152.

Janney, J. J., \& Folta, T. B. (2006). Moderating effects of investor experience on the signaling value of private equity placements. Journal of Business Venturing, 21(1), 27-44.

Kickstarter. (2020). Kickstarter Stats. https://www.kickstarter. com/help/stats?ref=global-footer. Accessed 28 December 2020

Kim, J.-Y. J., \& Miner, A. S. (2007). Vicarious learning from the failures and near-failures of others: Evidence from the US commercial banking industry. Academy of Management Journal, 50(3), 687-714.

Kirmani, A., \& Rao, A. R. (2000). No pain, no gain: A critical review of the literature on signaling unobservable product quality. Journal of marketing, 64(2), 66-79.

Kotha, R., \& George, G. (2012). Friends, family, or fools: Entrepreneur experience and its implications for equity distribution and resource mobilization. Journal of Business Venturing, 27(5), 525-543.

Kromidha, E., \& Robson, P. (2016). Social identity and signalling success factors in online crowdfunding. Entrepreneurship \& Regional Development, 28(9-10), 605-629.

Kunz, M. M., Bretschneider, U., Erler, M., \& Leimeister, J. M. (2017). An empirical investigation of signaling in reward-based crowdfunding. Electronic Commerce Research, 17(3), 425-461.

Lagazio, C., \& Querci, F. (2018). Exploring the multi-sided nature of crowdfunding campaign success. Journal of Business Research, 90, 318-324.

Lerner, M., \& Almor, T. (2002). Relationships among strategic capabilities and the performance of women-owned small ventures. Journal of small business management, 40(2), $109-125$.

Mason, C. M., \& Harrison, R. T. (2004). Improving access to early stage venture capital in regional economies: A new approach to investment readiness. Local Economy, 19(2), 159-173.

Massa Saluzzo, F., \& Alegre, I. (2021). Supporting entrepreneurs: The role of third-party endorsement in crowdfunding 
platforms. Technological Forecasting and Social Change, 162,120402 . https://doi.org/10.1016/j. techfore.2020.120402.

McKenny, A. F., Allison, T. H., Ketchen, D. J., Short, J. C., \& Ireland, R. D. (2017). How should crowdfunding research evolve? A survey of the Entrepreneurship Theory and Practice editorial board. Entrepreneurship Theory and Practice, 41(2), 291-304.

Mitteness, C. R., Baucus, M. S., \& Sudek, R. (2012). Horse vs. jockey? How stage of funding process and industry experience affect the evaluations of angel investors. Venture Capital, 14(4), 241-267.

Mochkabadi, K., \& Volkmann, C. K. (2020). Equity crowdfunding: a systematic review of the literature. Small Business Economics, 54(1), 75-118.

Mollick, E. (2014). The dynamics of crowdfunding: An exploratory study. Journal of Business Venturing, 29(1), 1-16.

Mollick, E., \& Nanda, R. (2015). Wisdom or madness? Comparing crowds with expert evaluation in funding the arts. Management Science, 62(6), 1533-1553.

Mueller, B. A., \& Shepherd, D. A. (2014). Making the most of failure experiences: Exploring the relationship between business failure and the identification of business opportunities. Entrepreneurship Theory and Practice. https://doi. org/10.1111/etap.12116.

Nahapiet, J., \& Ghoshal, S. (1998). Social capital, intellectual capital, and the organizational advantage. The Academy of Management Review, 23(2), 242-266.

Petitjean, M. (2018). What explains the success of reward-based crowdfunding campaigns as they unfold? Evidence from the French crowdfunding platform KissKissBankBank. Finance Research Letters, 26, 9-14.

Piva, E., \& Rossi-Lamastra, C. (2018). Human capital signals and entrepreneurs' success in equity crowdfunding. Small Business Economics, 51(3), 667-686.

Plummer, L. A., Allison, T. H., \& Connelly, B. L. (2016). Better together? Signaling interactions in new venture pursuit of initial external capital. Academy of Management Journal, 59(5), 1585-1604.

Ragin, C. C. (2008). Redesigning social inquiry: Fuzzy sets and beyond. University of Chicago Press.

Schneider, C. Q., \& Wagemann, C. (2012). Set-theoretic methods for the social sciences: A guide to qualitative comparative analysis. Cambridge University Press.

Schneider, M. R., Schulze-Bentrop, C., \& Paunescu, M. (2010). Mapping the institutional capital of high-tech firms: A fuzzyset analysis of capitalist variety and export performance. Journal of International Business Studies, 41(2), 246-266.

Siegel, R., Siegel, E., \& Macmillan, I. C. (1993). Characteristics distinguishing high-growth ventures. Journal of business Venturing, 8(2), 169-180.

Signori, A., \& Vismara, S. (2018). Does success bring success? The post-offering lives of equity-crowdfunded firms. Journal of Corporate Finance, 50, 575-591.

Skirnevskiy, V., Bendig, D., \& Brettel, M. (2017). The influence of internal social capital on serial creators' success in crowdfunding. Entrepreneurship Theory and Practice, 41(2), 209-236.

Soublière, J.-F., \& Gehman, J. (2020). The legitimacy threshold revisited: How prior successes and failures spill over to other endeavors on Kickstarter. Academy of Management Journal, 63(2), 472-502.

Spence, M. (1973). Job market signaling. Quarterly Journal of Economics, 87(3), 355-374.

Steigenberger, N., \& Wilhelm, H. (2018). Extending signaling theory to rhetorical signals: Evidence from crowdfunding. Organization Science, 29(3), 529-546.

Stuart, T. E., Hoang, H., \& Hybels, R. C. (1999). Interorganizational endorsements and the performance of entrepreneurial ventures. Administrative Science Quarterly, 44(2), 315-349.

UC, I. (2017). University of California, Irvine.2017. fsQCA. http:// www.socsci.uci.edu/ cragin/fsQCA/software.shtml.

Unger, J. M., Rauch, A., Frese, M., \& Rosenbusch, N. (2011). Human capital and entrepreneurial success: A meta-analytical review. Journal of Business Venturing, 26(3), 341-358.

Viotto da Cruz, J. (2018). Beyond financing: Crowdfunding as an informational mechanism. Journal of Business Venturing, 33(3), 371-393.

Vismara, S. (2016). Equity retention and social network theory in equity crowdfunding. Small Business Economics, 46(4), 579-590.

Vismara, S. (2019). Sustainability in equity crowdfunding. Technological Forecasting and Social Change, 141, 98-106.

Wallmeroth, J., Wirtz, P., \& Groh, A. P. (2018). Venture capital, angel financing, and crowdfunding of entrepreneurial ventures: A literature review. Foundations and Trends ${ }^{\circledR}$ in Entrepreneurship, 14(1), 1-129.

Wehnert, P., Baccarella, C. V., \& Beckmann, M. (2019). In crowdfunding we trust? Investigating crowdfunding success as a signal for enhancing trust in sustainable product features. Technological Forecasting and Social Change, 141, 128137.

Wright, F. (2017). How do entrepreneurs obtain financing? An evaluation of available options and how they fit into the current entrepreneurial ecosystem. Journal of Business and Finance Librarianship, 22(3-4), 190-200.

Zhang, J. (2011). The advantage of experienced start-up founders in venture capital acquisition: Evidence from serial entrepreneurs. Small Business Economics, 36(2), 187-208.

Zuckerman, E. W. (1999). The categorical imperative: Securities analysts and the illegitimacy discount. American Journal of Sociology, 104(5), 1398-1438.

Zunino, D. (2018). Socio-cognitive perspectives in business venturing. Copenhagen Business School (CBS).

Zvilichovsky, D., Inbar, Y., \& Barzilay, O. (2015). Playing both sides of the market: Success and reciprocity on crowdfunding platforms. SSRN Electronic Journal. https://doi.org/10.2139 /ssrn.2304101.

Publisher's note Springer Nature remains neutral with regard to jurisdictional claims in published maps and institutional affiliations. 